\title{
Some Lessons from a 3-Year Experiment of Problem- Based Learning in Physics in a French School of Engineering
}

\author{
Philippe Ageorges, Adriana Bacila, Géraldine Poutot, Bernard Blandin* \\ Cesi School of Engineering, 30 rue Cambronne, F-75015 Paris, France \\ *Corresponding author: bblandin@cesi.fr
}

Received May 05, 2014; Revised July 11, 2014; Accepted July 15, 2014

\begin{abstract}
In this experiment, a Problem-based learning methodology (PBL) is used to teach physics to engineering students. The efficiency of PBL is measured and compared to traditional teaching methods. Our experiment shows no major differences in terms of knowledge acquisition, conceptualization and physical reasoning. On the other hand, PBL shows an influence on cross-knowledge acquisition. Implementing PBL with large groups of students has faced many challenges. PBL is a highly destabilizing and demanding method for students. To make them accept the method and the effort, PBL method has been adapted with closer guidance from tutors. A preparatory program has also been set up. The experiment also shows that the lecturers' acceptance and understanding are key success factors. It is a long process for experienced lecturers to move from a teacher-centered teaching method to a student-centered pedagogy. Lecturers need strong support and guidance from PBL experts but also from the faculty itself. More complex timetables have been designed to manage large groups of students with limited staff. The constraint is to maintain the same number of teaching hours as for traditional teaching. If difficulties have appeared throughout this experiment, benefits have been noticed over time. Students develop problem solving methodologies as well as communication and organizational skills. These benefits have been noticed by companies and students' acceptance has improved over time.
\end{abstract}

Keywords: problem based learning, PBL in large group settings, physics, results of an experiment, students' acceptance, teachers' acceptance, engineering students

Cite This Article: Philippe Ageorges, Adriana Bacila, Géraldine Poutot, and Bernard Blandin, "Some Lessons from a 3-Year Experiment of Problem-Based Learning in Physics in a French School of Engineering." American Journal of Educational Research, vol. 2, no. 8 (2014): 564-567. doi: 10.12691/education-2-8-1.

\section{Introduction}

For the past three years, CESI, an engineering school in France, has developed a Problem-based learning methodology (PBL) in the field of physics. The main objectives are to make physics more attractive to students as well as helping them to develop professional skills. The first steps of this development program were presented at the GIREP conferences in 2010 [1] and 2012 [2]. This program has been further developed in all fields of physics and extended to a larger group of students.

There are few descriptions of the use of PBL in higher education in France. The purpose of this paper is to describe the PBL implementation and present results obtained in comparison with traditional teaching methods.

Acceptance of the method by students and teachers, as well as monitoring many PBL groups has also been the challenge of this experiment [3]. Staff and students feedback is presented in this paper.

\section{The Background}

\subsection{Problem One}

Over the years, lecturers noticed a declining interest in studying sciences [4]. If students are keen to discover new subjects, they are not motivated to understand basic concepts of science. In most cases, they are unable to use them in real-life situations.

Another important issue for teachers is to keep students' attention while competing with modern distractions. Students cannot listen and concentrate for more than 30 to 45 minutes, and they almost constantly connect to their mobile phone and other portable devices during class.

For all these reasons, we wanted to find a way to stimulate students' interest and increase students' skills in physics.

\subsection{Problem Two}

Students involved in this experiment are engineering students at Bachelor level. They are all enrolled in a specific Master of engineering program that combines full-time periods of study and full-time periods of work in a company. Since they are employed by a company, 
students are expected to quickly develop professional skills in order to complete their work experience with success.

The most common skills required by companies are not only technical expertise, but also reasoning abilities, communication skills and organizational skills. All these skills could not be developed with traditional teaching methods. Common feedback from companies is: "your students know things but cannot use them".

All these facts pushed us to explore teaching methods that would help students develop professional skills. This is why an active learning approach based on Problem Based Learning (PBL) was chosen and developed.

The objectives and the hypotheses of this experiment are:

- PBL will be tested in physics during the first year,

- PBL's efficiency will be measured and compared to traditional methods,

- PBL should improve conceptualization and comprehension in mechanics, thermodynamics and electromagnetism,

- PBL should improve students' motivation.

\section{PBL Implementation}

\subsection{The PBL Sequences}

Six specific problem situations were developed to cover the physics program of a whole semester (two in mechanics, two in electricity and two in thermodynamics). For each problem, the PBL Session was divided into five sequences. At first, the class was divided into groups of 10 to 12 students and each have to precisely define the issues which are to be addressed in the problem (1). In the second sequence, students have to use given materials to learn all the physics principles required in the problem (2). The third sequence is devoted to the resolution of exercises based on the physics principles (3). In the fourth sequence, students have time to solve the problem individually (4). The final sequence allows students to synthesize answers and demonstrate that the required learning outcomes are acquired (5). All sequences are supervised by a tutor.

The following table shows the timetable for two problem situations.

Table 1. The five PBL sequences for two different problem situations conducted consecutively

\begin{tabular}{|c|c|c|c|c|c|c|}
\hline & Monday & Tuesday & Wednesday & Thursday & Friday & Monday \\
\hline \multicolumn{7}{|l|}{$8-9$ am } \\
\hline 9-10 am & & (1) & \multirow{3}{*}{ (4) } & (5) & \multirow{3}{*}{ (4) } & (5) \\
\hline $10-11 \mathrm{am}$ & & \multirow{2}{*}{ (2) } & & (1) & & \\
\hline $11-12 \mathrm{am}$ & & & & (2) & & \\
\hline $1-2 \mathrm{pm}$ & & \multirow{2}{*}{ (2) } & & \multirow{2}{*}{ (2) } & & \\
\hline $2-3 \mathrm{pm}$ & & & & & & \\
\hline 3-4 pm & & \multirow{2}{*}{ (3) } & & \multirow{2}{*}{ (3) } & & \\
\hline $4-5 \mathrm{pm}$ & & & & & & \\
\hline
\end{tabular}

\subsection{Implementing PBL with a Large Class}

The development of the PBL methodology has faced difficulties due to the large number of students, the limited number of teaching staff and the school's economic constraints [5]. The number of teaching hours cannot be higher with PBL.

In traditional teaching, one person can easily teach to 75 students sitting in a lecture theater. Then the class is divided into 2 or 3 smaller groups for problem classes and practical work. With the PBL approach, it is not straightforward to handle 6 groups of 12 to 13 students.

To solve these difficulties, one has to consider the role of the PBL tutors. The efficiency of the methodology relies on the people in charge of it. All PBL tutors must agree with the PBL methodology. Most of them have been used to traditional teaching and they usually enjoy it. Their role differs drastically in an active learning approach. Their role is to facilitate and guide students by means of questions. No answers should be given; students should find solutions by themselves. Tutors have to accept that they are not the heart of the learning process.

Therefore, one has to realize that certain sequences require close supervision by a tutor (sequences 1,3 and 5) while others require less assistance (sequence 4 ) or even no assistance at all (sequence 2). For instance, sequence 1 and 5 last one hour each. Two tutors can repeat these sequences with different groups at a time. Sequence 3 lasts two hours and can be seen as a more traditional exercise session. The tutor runs the sequence with 3 groups at the same time. In sequence 4, tutors are present but assist students on demand only. To make all that fit with the same teaching hours and the same number of staff as used for traditional teaching requires specific timetables for each group and for each tutor. When tutors have to repeat the same sequence several times in a row, each group has to go from one sequence to the next. As a consequence, groups will not start a particular PBL session at the same time. The class timetable turns out to be much more complex with the PBL methodology.

Table 2. PBL Timetable for 3 different groups and one lecturer following two consecutive exercises

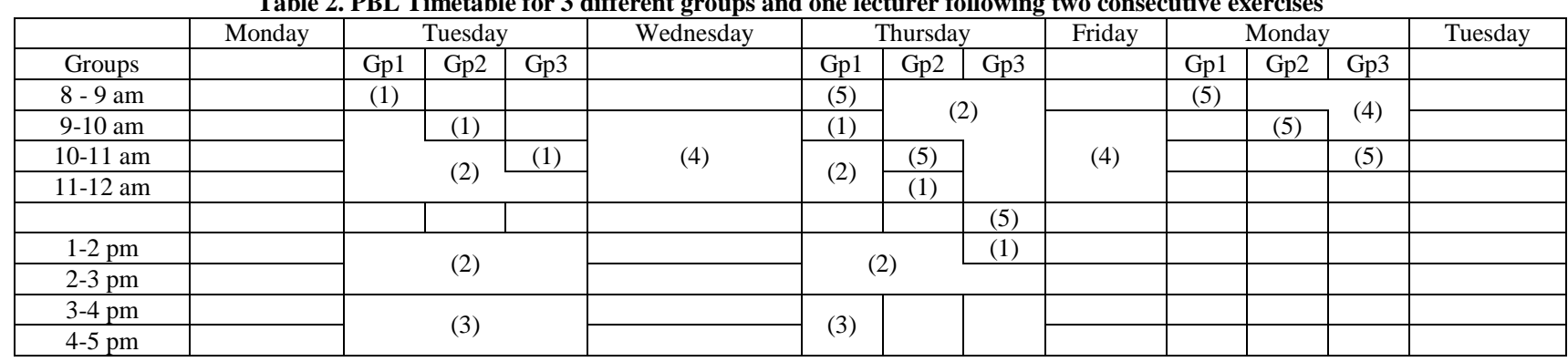




\subsection{Example of a PBL Study Case}

In mechanics, students solved a problem that occurred in one of the French railway hump yard. Wagons rushed down the hump with a final velocity that was too high. They ended their course with too much energy for the bumpers. Students were able to analyse the problem using data provided by the railway company and the wagon manufacturer. One expected learning outcomes was: potential energy is independent of the path taken by the wagon.

All PBL study cases were based on real company problems.

\section{Quantitative Results}

The experiment aimed at comparing the PBL method with traditional teaching. The program in mechanics was chosen for this quantitative experiment [2].

Three different campuses participated in this experiment: Campus 1 with 120 students, Campus 2 with 30 students and Campus 3 with 60 students. In each campus, students were divided into two groups of identical size. One of the groups did traditional teaching while the other group participated in the Problem-Based Learning sessions. To compare both approaches, the following protocol was set-up: The students take the same exams, one after each module, and take a test in order to evaluate progress in mastering the concepts and principles of Newtonian physics: the Force Concept Inventory (FCI) developed by Hestenes [6]. The FCI was taken by all the students before and after the course. The results are presented in Table 3 and Figure 1.

Table 3. Results of theFCI Pre-test (Pre-T) and Post-Test (Post-T) for both traditional teaching(TT) and PBL [2]

\begin{tabular}{|c|c|c|c|c|c|c|}
\hline & \multicolumn{2}{|c|}{ Campus 1 } & \multicolumn{2}{c|}{ Campus 2 } & \multicolumn{2}{c|}{ Campus 3 } \\
\hline & Pre-T & Post-T & Pre-T & Post-T & Pre-T & Post-T \\
\hline TT & Not available & $43 \%$ & $45 \%$ & $47 \%$ & $31 \%$ & $32 \%$ \\
\hline PBL & $33 \%$ & $36 \%$ & $35 \%$ & $39 \%$ & $36 \%$ & $48 \%$ \\
\hline
\end{tabular}

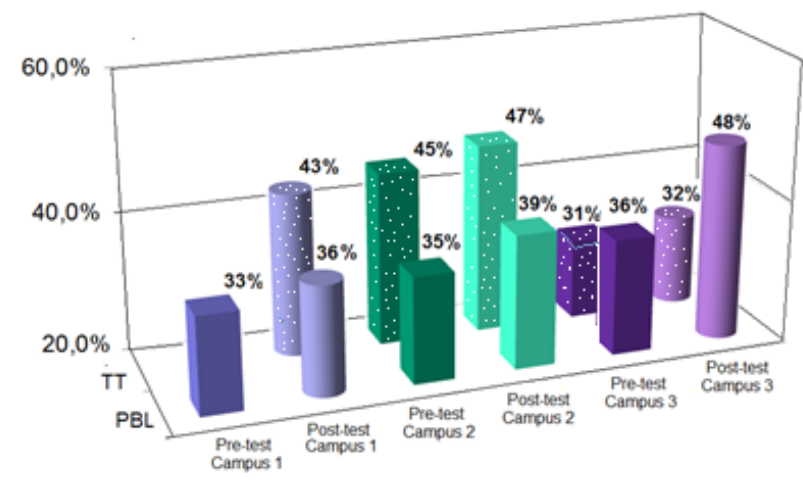

Figure 1. Results of the FCI before (Pre-test) and after the course (Posttest) for both Traditional Teaching (TT) and PBL [2] (No TT Pre-test data available for campus 1)

Acquired competences are validated by the exams. The evaluation of the learning outcomes uses a Rubrics grid [7] which measures the achievement of each learning objective. This grid is based on Bloom's taxonomy [8]. Marks obtained for the exam after the course are synthesized below for each campus. The PBL group is noted PBL and the traditional teaching group is TT. Results are presented in Table 4 and Figure 2.
Table 4. Exam results obtained in all 3 campuses for both Traditional Teaching (TT) and PBL [2]

\begin{tabular}{|c|c|c|c|}
\hline & Campus 1 & Campus 2 & Campus 3 \\
\hline TT & $(66 \pm 20) \%$ & $(60 \pm 24) \%$ & $(48 \pm 15) \%$ \\
\hline PBL & $(52 \pm 13) \%$ & $(61 \pm 29) \%$ & $(53 \pm 20) \%$ \\
\hline
\end{tabular}

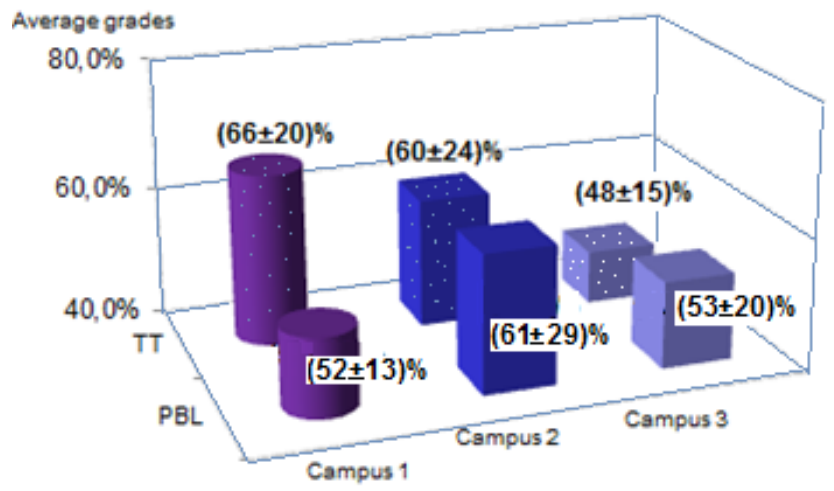

Figure 2. The exam results for both traditional teaching (TT) and PBL [2]

When comparing these two methods, results in mechanics show that PBL does not improve knowledge acquisition, nor does it have an influence on conceptualization [2]. These results do not show us that PBL is more efficient than traditional teaching. Major influence is seen on a qualitative point of view.

\section{Qualitative Results}

\subsection{Students' Attitude with PBL}

Compared to traditional teaching, the majority of students are highly involved in solving PBL problems. Students recognise that they have never worked that much in sciences. Solving problems is seen as a challenging task, however, moving from a comfortable passive methodology to an active one has been extremely demanding and tiresome for most of them. One major difficulty in this experiment was the students' negative reaction to PBL. Common complaints are: "We need lectures to learn"; "We need teachers to learn"; "Tell me what I should do?"; "What is the answer?"; "I have to learn by myself, teachers are doing nothing”...

To improve students' acceptance and, therefore, the efficiency of active learning, it is important to prepare them for this new methodology. A preparatory course is necessary to make them move from the long-term use of traditional teaching to a scheme that best fits company needs. In this course, students experience PBL with two problem situations and then, they have to analyze and identify the strength of the PBL methodology in relation to the skills of an engineer. As soon as they understand the use of PBL, students will accept the efforts required. This acceptance may take some time for certain students, so the tutor has to regularly explain and justify the different steps. At the very least, a group discussion has to take place at the end of each sequence 5 . Individual feedback is also a key element to reassuring destabilized students.

Students' acceptance in adapting the PBL methodology has also improved over the years. Feedback from student showed the necessity for having more guided exercises on the learning outcomes. This is why sequence 3 has been enriched with a series of exercises and stronger guidance from tutors. 
The students' acceptance improved with time. Those who criticized the PBL method while there were doing it realized its benefits afterwards. Working in a company enhances the acceptance process. Companies often mention that PBL students are more autonomous in solving complex problems. They develop pro-active behaviour as well as good professional skills in terms of communication and methodology to organize their work [9].

Over three years, students' appreciation of PBL has moved from $65 \%$ of acceptance to $93 \%$.

\subsection{Lecturers' New Role}

With PBL, lecturers have to understand and accept a new role. PBL tutors organise the learning process and facilitate students in their learning. Experienced lecturers find it hard to move from a "one man show" teaching approach to a PBL one. PBL is centred on the student and on the problem. PBL tutors do not transmit knowledge but enable students to acquire knowledge. PBL students learn in small groups guided by a tutor. Tutors guide the group in defining self-directed learning objectives. These objectives guide students throughout their learning process. PBL tutors guide the group with provoking comments or counter-questions. They must use their expertise in a subtle and limited way. Experience shows that it is often tempting to intervene when students' discussions enter tutors' field of expertise. Tutors should not control the learning process. This experiment shows that most lecturers used to the traditional approach often find it inconceivable to not interfere in an authoritarian way.

Creating PBL problems is an extremely stimulating activity but requires a lot of time and energy. A good PBL problem involves a real situation that engages students to acquire different learning outcomes. A PBL problem does not have one solution [10]. It is a real challenge to write problems that stimulate students' curiosity and encourage learning. The time it takes to create a problem and select all appropriate resources leads to lecturers being discouraged.

Moving away from traditional teaching to PBL is like moving to a completely new teaching paradigm for experienced lecturers. They need to be guided and supported in this new approach. Support and understanding must also come from the faculty heads and administrative staff. This experiment shows that working in teams is the best way to understand and move on with the PBL methodology.

\section{Conclusion}

Traditional teaching and PBL results show similar knowledge acquisition and similar level of conceptualization. However, PBL helps develop problem solving and professional skills.

Students have never worked that much. Most of them are stressed because of the necessity to adapt to new ways of learning. However, the more they work with PBL, the better, faster and easier it becomes for them. They develop a high level of autonomy.

Implementing PBL requires the whole institution's support, and a high involvement of tutors.

PBL methodology is now used by many physics tutors in CESI. Different classes have practiced the methodology, and the "guinea pig" feeling of first generation students is over. The school's future project is to develop problem situations in other fields as well as project-based learning in physics and technology.

\section{References}

[1] Blandin, B., "Learning Physics: a Competency-based Curriculum using Modelling Techniques and PBL Approach”, The GIREP ICPE - MPTL International Conference, Reims, France, 22-27 August 2010. [Online]. Available at: http://www.univreims.fr/site/evenement/girep-icpe-mptl-2010-reims-internationalconference/gallery_files/site/1/90/4401/22908/29321/29590.pdf[A ccessed July 7, 2014]

[2] Bacila, A., Poutot, G., Ageorges, P., Blandin, B., "Problem-based Learning in mechanics: some results of a controlled experiment", Proceedings of The World Conference On Physics Education, 2012, Pegem Akademi, 405-412, 2014. [online]. Available at:http://www.wcpe2012.org/proceedings.html [Accessed July 7, 2014].

[3] Wilkerson, L. A., Gijselaers, W. H., "Bringing Problem-Based Learning to Higher Education: Theory and Practice”, Jossey-Bass Publishers, San Fransisco, 68, Winter 1996, 91-99.

[4] Convert, B., "Disaffection for Science Studies: Paradoxes of the French Case“, Revue Française de Sociologie, Presses de Sciences Po, 46 (5), 59-77, 2005. [Online] Available at: http://www.cairn.info/zen.php?ID_ARTICLE=RFS_465_0059\#no 1 [Accessed July 7, 2014].

[5] Pastirik, P.J., "Using Problem-Based Learning in a Large Classroom”, Nurse Education in Practice, 6, 261-267, 2006.

[6] Hestenes, D., Wells, M., Swackhamer, G., "Force Concept Inventory”, The Physics Teacher, 30, 141-151, March 1992.

[7] Allen, D., Tanner, K., Rubrics "Tools for Making Learning Goals and Evaluation Criteria Explicit for Both Teachers and Learners”, CBE_Life Sciences Education, 5 (3), 197-203, Fall 2006.

[8] Bloom, B. S., Krathwohl, D. R.,The classification of educational goals, by a committee of college and university examiners, New York, Longmans, 1956.

[9] Drohan, S., Maufette, Y., Allard, J.-L., "Employers perspectives on Problem-Based Learning Initiatives”, in Barrett, T. \&Moore, S., New Approaches to Problem-Based Learning: Revitalizing your Practice in Higher Education, Routledge, New-York, 2011, 87-99.

[10] Savery, J.R., "Overview of Problem-based Learning: Definitions and Distinctions”, The Interdisciplinary Journal of Problem-based Learning, 1 (1), 9-20, Mai 2006. 